\title{
STUDY OF CONSEQUENCE ON TRAFFIC DENSITY PATTERNS IN THE PERFORMANCE OF ROUTING PROTOCOLS FOR VEHICULAR AD-HOC NETWORK
}

\author{
RAHUL KUMAR CHAWDA ${ }^{1} \&$ GHANSHYAM SINGH THAKUR ${ }^{2}$ \\ ${ }^{I}$ Research Scholar, Department of Computer Application, Maulana Azad National Institute of Technology, \\ Bhopal, India 462003 \\ ${ }^{2}$ Assistant Professor, Department of Computer Application, Maulana Azad National Institute of Technology,
} Bhopal, India 462003

\begin{abstract}
VANET (Vehicular Ad-Hoc Network) ${ }^{[1]}$ which is a sub-sort of the MANET (mobile ad-hoc networks) gives wireless communication between the vehicle to vehicle (V2V), vehicle to infrastructure (V2I), and vehicles to the Road Side Units $(\mathrm{RSU})^{[2] .}$ In Vehicular Ad-Hoc Network, the correspondence between the vehicles is utilized for different purposes like security, solace, and amusement. $\boldsymbol{n}$ this paper, we've evaluated performance of varied routing protocols for VANET in several traffic patterns. The vehicular movements are supported intelligent driver model with road intersection. Our objective is to supply a comparative analysis among various unplanned routing protocols supported packet delivery ratio. Routing protocols are LAC, LARI, AODV and DSR protocols. The traffic patterns categorize as sparse, moderate and dense based on the number of nodes. The results show that LAC Routing protocol outperforms others. The maximum packet delivery ratio obtained is $79.5 \%$ in the sparsely populated network. We have used Glomosim-2.03 ${ }^{[11]}$, MobiSim ${ }^{[12],}$ ${ }^{[13]}$ and MATLAB ${ }^{[10]}$ simulator for our analysis
\end{abstract}

KEYWORDS: IDM (Intelligent Driver Model), Intersection Point, Routing Protocol, Packets Delivery Ratio

Received: Jun 09, 2020; Accepted: Jun 29, 2020; Published: Aug 13, 2020; Paper Id.: IJMPERDJUN2020760

\section{INTRODUCTION}

From the past century, mobile communication methods have converted the automotive sector by offering communication between various devices anytime. This ease of communication enables precious data to be exchanged between devices on the go. The fast and efficient transfer of real-time bases of data has turned out to be a fresh sector paradigm. Accordingly, advances in IT and communication have readily endorsed the concept of mobile device interaction. Among these advances, the Vehicle Ad-hoc Networks (VANET) concept came into the spotlight, opening up fresh opportunities for the use of security apps. Ad-hoc Vehicle Networks (VANET) is usually described as a unique type of network where nodes are represented as' cars' with the ability to transmit information across the network. VANET is also regarded as a Mobile Ad-Hoc Network or MANET replacement. Due to its greater node mobility and dynamic topology, there has been significant awareness and advancement in the field of VANET. VANET offers communication between cars and roadside base stations (RSU) with the objective of ensuring effective and secure transport. 
Each participating vehicle is transformed into a router or wireless node that can communicate around $100 \mathrm{~m}$ to $300 \mathrm{~m}$ and become a component of the network. In case cars drop out of the spectrum, the network will be thrown out. If it goes within the range to form a VANET, any vehicles can join the network. Specific transmission among such a vehicle and another vehicle is termed as Vehicle to Vehicle (V2V), while communication among a vehicle and an infrastructure including a roadside unit (RSU) is usually recognized as Vehicle to Infrastructure (V2I) communication. The real aim of VANET is to enable wireless communication between cars on the highway, including wireless detectors on the roadside, to guarantee driving safety and dynamic routing planning, to enable mobile sensing and entertainment in the car.

Even though VANET is considered as a type of MANET, it has its own particular features that make it different from MANET. These characteristics include:

- Each vehicle is turned into a router or wireless node with the capability to connect and become a part of a network in the range of approximately 100-300m.

- Network topology changes as the vehicles fall out of range or new vehicles join the network, thus making the network density vary according to traffic density. For example, network density can be very high when in a traffic jam, or very low in suburban traffic.

- Mobility in a VANET environment is predictable because vehicles are constrained by road signs and traffic lights and how they can respond to other moving vehicles.

- As vehicles are equipped with long life batteries, power is not a critical challenge as it is in MANET.

- $\quad$ Some VANET applications have strict delay requirements to prevent drivers from possible accidents.

- VANET leverages different types of wireless technologies (such as Wi-Fi, 802.11p, WiMAX, 3G among others), that had been extensively studied. These wireless technologies are an important component of Intelligent Transportation Systems.

In this paper, we have evaluated the performance ad hoc routing protocols in different traffic density with real vehicular traces. We discuss the related work in section II. In the section III, presents various basic assumptions and section IV shows simulation results and analysis. Finally, in section V this paper is concluded.

\section{RELATED WORKS}

For VANET, wireless communication is considered as a significant technology for supporting the achievement of varied applications as well as services. Though, because of VANET characteristics like enhanced dynamic topology and irregular connectivity, MANET traditional routing algorithms are not obtainable for main application scenario.

Therefore, authors don't put some effort for improving traditional algorithms with designing novel ones for the reliability of communication could be guaranteed. On the basis of amount of senders and receivers concerned, routing approaches could be categorized into three types: broadcast/ geo-cast, multicast, and unicast approaches. 


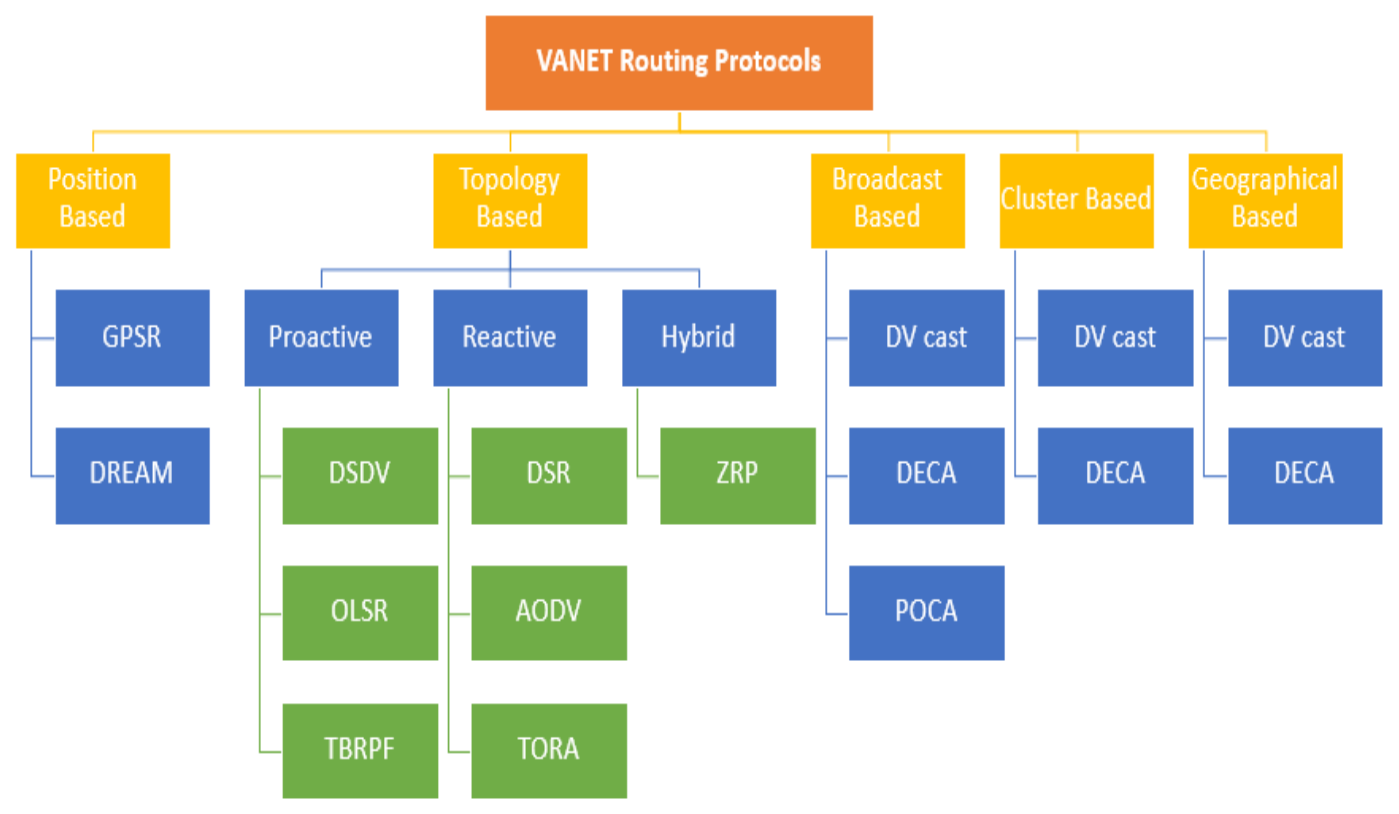

Figure Error! No text of specified style in document.: VANET Routing Protocols.

Table 1

\begin{tabular}{|c|c|c|c|}
\hline $\begin{array}{l}\text { Routing } \\
\text { Protocols }\end{array}$ & Description & Pros & Cons \\
\hline $\begin{array}{c}\text { Position } \\
\text { Based }\end{array}$ & $\begin{array}{l}\text { In this system the source end } \\
\text { communicate with the destination point } \\
\text { on the basis of position of vehicle rather } \\
\text { than the address. } \\
\text { It is comprises of mainly three elements } \\
\text { named as beaconing, position services } \\
\text { and forwarding. For selecting the } \\
\text { positioning of different vehicles GPS } \\
\text { (Global Positioning System) is used. } \\
\text { An example of this routing protocol is } \\
\text { DREAM (Distance routing effect } \\
\text { algorithm for mobility) and GPSR } \\
\text { (Greedy Perimeter stateless routing). }\end{array}$ & $\begin{array}{l}\text { It is mostly used in highway } \\
\text { where vehicles are moving } \\
\text { with high speed and road has } \\
\text { very less objects to disturb the } \\
\text { communication. } \\
\text { There is no need to make and } \\
\text { maintain the route from source } \\
\text { to destination. } \\
\text { High stability. } \\
\text { Less processing overhead. }\end{array}$ & $\begin{array}{l}\text { GPS is required. } \\
\text { GPS system does not } \\
\text { operate in tunnel as it } \\
\text { does not catch } \\
\text { satellite signal. } \\
\text { Deadlock state may } \\
\text { exist sometimes. }\end{array}$ \\
\hline $\begin{array}{l}\text { Topology } \\
\text { Based }\end{array}$ & $\begin{array}{l}\text { This method used the information } \\
\text { presented in the network in order to } \\
\text { transmit packet from source node to end } \\
\text { node. }\end{array}$ & $\begin{array}{l}\text { A route from source point to } \\
\text { the end point is making by } \\
\text { sure. } \\
\text { By using this approach uni- } \\
\text { cast and multicast data can be } \\
\text { transmitted. } \\
\text { Less resource consumption } \\
\text { A small amount of bandwidth } \\
\text { consumption. }\end{array}$ & $\begin{array}{l}\text { Route discovery } \\
\text { process and delay } \\
\text { maintenance exist } \\
\text { which may cause } \\
\text { more overhead. } \\
\text { If the movement of } \\
\text { vehicles is fast then it } \\
\text { might be failed to } \\
\text { find the route. } \\
\text { redundant flooding }\end{array}$ \\
\hline
\end{tabular}




\begin{tabular}{|c|c|c|c|}
\hline $\begin{array}{l}\text { Broadcast } \\
\text { Based }\end{array}$ & $\begin{array}{l}\text { This approach is used to flood the data in } \\
\text { the whole network nodes. } \\
\text { This protocol is used in case when the } \\
\text { destination node is out of approach from } \\
\text { the source node. } \\
\text { Thus it find application is the road safety, } \\
\text { trafiic control, emergency warning etc. } \\
\text { The protocols such as (Distributed } \\
\text { vehicular broadcast) DV-CAST, (Position } \\
\text { aware reliable broadcasting) POCA and } \\
\text { (Density aware reliable broadcasting) } \\
\text { DECA come under this category. }\end{array}$ & $\begin{array}{l}\text { More reliable as the data is } \\
\text { transmitted through various } \\
\text { nodes. } \\
\text { Less overhead. }\end{array}$ & $\begin{array}{l}\text { Require more } \\
\text { bandwidth. } \\
\text { Many duplicate } \\
\text { packets reached to } \\
\text { the node. }\end{array}$ \\
\hline $\begin{array}{l}\text { Cluster } \\
\text { Based }\end{array}$ & $\begin{array}{l}\text { In this routing approach the vehicles with } \\
\text { the same features such as speed, direction } \\
\text { etc. makes a cluster. } \\
\text { To make communication among a } \\
\text { number of clusters a cluster head is } \\
\text { selected within every cluster that make } \\
\text { communication possible. } \\
\text { If the data is transmitted within the cluster } \\
\text { then the route is created directly from } \\
\text { source to destination but in case if the } \\
\text { destination node is outside the cluster } \\
\text { then the route is created by the cluster } \\
\text { head. } \\
\text { The examples of cluster head are COIN } \\
\text { (Clustering for open inter vehicular } \\
\text { communication network) and LoRACBF. }\end{array}$ & $\begin{array}{l}\text { High scalability for big } \\
\text { networks. }\end{array}$ & $\begin{array}{l}\text { More overhead } \\
\text { Delay is high }\end{array}$ \\
\hline Geo-Cast & $\begin{array}{l}\text { It uses mobile just in time multicasting to } \\
\text { transferring message from source to } \\
\text { destination. } \\
\text { Its main constraints is time. }\end{array}$ & $\begin{array}{l}\text { Less overhead and congestion. } \\
\text { Consistent packet delivery. }\end{array}$ & $\begin{array}{l}\text { Connection } \\
\text { disconnection } \\
\text { problem occurs that } \\
\text { may lead to the } \\
\text { transmission delay. }\end{array}$ \\
\hline
\end{tabular}

These days the majority of the academicians, scientists, and industry people proposed and executed different sorts of protocols for effective message transmission in Vehicular Ad-Hoc Network. The exhibition LAR1 ${ }^{[7]}$ protocol with DSR ${ }^{[8]}$ and AODV ${ }^{[9]}$ LAC $^{[10]}$ in profoundly thick specially appointed systems assessed in ${ }^{[2]}$ dependent on vitality utilization. In ${ }^{[2]}$ creators show that LAR1 performs better than DSR and AODV protocol. However, in low-thickness traffic, DSR performs superior to other people. In ${ }^{[3]}$ creators show a wide examination of their proposed protocol Geographic Source Routing (GSR) with DSR, AODV for VANET in a city domain. The sensible vehicular traffic is taken for a specific city with a genuine guide. Here, GSR accomplishes preferable execution over DSR and AODV. In ${ }^{[4,5]}$ proposed distinctive adjusted LAR calculations for VANET. The proposed calculations decrease course demand overhead when contrasted with unique LAR perform better in thick and profoundly powerful impromptu systems. In ${ }^{[6]}$ creators propose an eager adaptation of the LAR protocol known as GLAR (Greedy Location-Aided Routing Protocol). In the GLAR strategy, to discover a course among source and goal, a standard is drawn between them. The course demand bundles are communicated inside the solicitation zone. The outcomes got uncover that GLAR requires less number of course revelation bundles and expands normal system course lifetime. The greater part of the previously mentioned presentation investigation utilizes the arbitrary waypoint versatility model. The protocols proposed in ${ }^{[3], ~[4], ~[5], ~ a n d ~}{ }^{[6]}$ didn't consider organized city situations for the exhibition examination of the LAR1 protocol in VANET. In ${ }^{[13]}$ investigation of routing protocols dependent on genuine guide, information is finished. 


\section{ASSUMPTIONS}

We have considered different traffic situations dependent on their density. For the most part, traffic design differs for the duration of the day. Traffic is high during the available time, exceptionally less during late night and the remainder of the time traffic stays moderate appeared in Table-2. Vehicles are furnished with GPS receivers, advanced maps, discretionary sensors, and On-Board Units (OBU). The area data of all vehicles can be gathered through GPS receivers. The Intelligent Driver Model with Intersection Management (IDM_IM) portability model is a naturally visible vehicle following a model that adjusts a vehicle speed as indicated by different vehicles driving ahead. IDM-IM model uses a very little arrangement of parameters, which can be assessed with the assistance of genuine traffic estimations ${ }^{[11,12]}$.

Table 2: Traffic Based on Node Density

\begin{tabular}{|l|c|}
\hline \multicolumn{1}{|c|}{ Category of Traffic } & No of Nodes \\
\hline Sparse & $<50$ \\
\hline Moderate & $>50$ \\
\hline Dense & $>100$ \\
\hline
\end{tabular}

\section{SIMULATION AND RESULT}

We have used the network simulations work done in Glomosim-2.03 ${ }^{[11]}$, MobiSim ${ }^{[12],[13]}$ and MATLAB ${ }^{[10]}$. The vehicular movements and scenarios are generated using VANET MobiSim ${ }^{[11], ~[12]}$.Routing protocols considered for the examination are LAR1 ${ }^{[6]}$, DSR ${ }^{[7]}$, AODV $^{[8]}$ and LAC ${ }^{[10] .}$ Table 3 shows evaluation framework with different Routing protocols.

Table 3: Simulation Parameters

\begin{tabular}{|l|c|c|c|c|}
\hline \multicolumn{1}{|c|}{ Routing Protocol } & AODV & DSR & LAR1 & LAC \\
\hline Height & $1000 \mathrm{~m}$ & $1000 \mathrm{~m}$ & $1000 \mathrm{~m}$ & $1000 \mathrm{~m}$ \\
\hline Width & $1000 \mathrm{~m}$ & $1000 \mathrm{~m}$ & $1000 \mathrm{~m}$ & $1000 \mathrm{~m}$ \\
\hline \multirow{2}{*}{ Number of Vehicles } & $50,60,80,100,120$, & $50,60,80,100$, & $50,60,80,100$, & $50,60,80,100$, \\
& 150 & 120,150 & 120,150 & 120,150 \\
\hline Coverage Limit & $200 \mathrm{~m}$ & $200 \mathrm{~m}$ & $200 \mathrm{~m}$ & $200 \mathrm{~m}$ \\
\hline Transmission of RSU & Radius of $200 \mathrm{~m}$ & Radius of $200 \mathrm{~m}$ & Radius of $200 \mathrm{~m}$ & Radius of $200 \mathrm{~m}$ \\
\hline Vehicle Deployment & Randomly & Randomly & Randomly & Randomly \\
\hline Packet Size & 1000 & 1000 & 1000 & 1000 \\
\hline Data Packet Sizes & 1000 Bytes & 1000 Bytes & 1000 Bytes & 1000 Bytes \\
\hline
\end{tabular}

The exhibition of the protocol relies upon different boundaries picked in the simulation. There are different boundaries that legitimately impact packet delivery are nodes speed, traffic pattern, packet size, number of nodes, transmission range, and structure of the system. The PDR can be acquired from the all outnumber of data packets showed up at goals separated by the all-out data packets sent from sources. We have introduced here the PDR dependent on various traffic classes as appeared in Table - I.

\section{Sparse Traffic Scenario}

Figure. 2 shows the PDR of 50 nodes with changing node speed. The results show that PDR of LAC achieved nearly $79.52 \%$ of PDR when node speed is $10 \mathrm{~m} / \mathrm{s}$. The performance of the protocol is quite consistent with various node speeds. In this case, LAC outperforms other protocols. The minimum achieved PDR is $55 \%$ for DSR protocol when node speed is $30 \mathrm{~m} / \mathrm{s}$. 


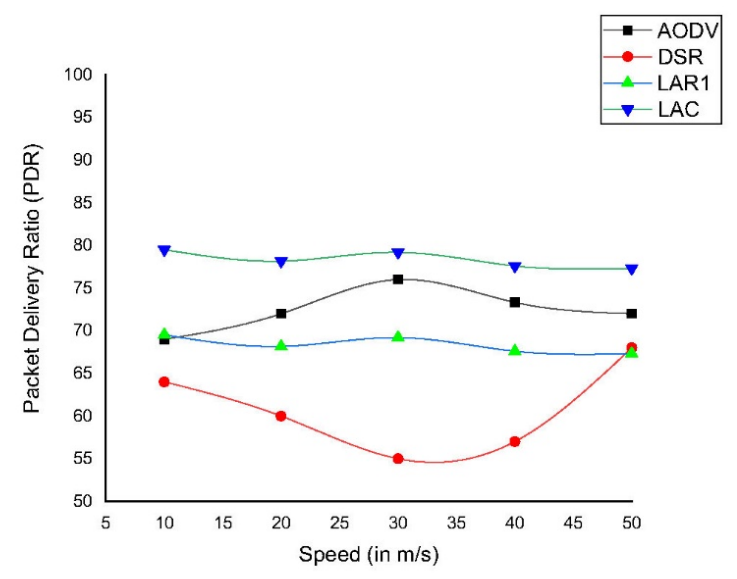

Figure 2: PDR for 50 Nodes with Changing Node Speed.

\section{Moderate Traffic Scenario}

In this traffic scenario, we have considered 60, 80 and 100 nodes for the analysis of the various routing protocols with changing node density.Figure. 3 shows that PDR for 60 nodes with various node speeds. Here, PDR of LAC protocol is high as compared to other protocol with changing node speed. The performance of LAC throughout various speeds is constant. In case of AODV protocol performance degraded after node speed $30 \mathrm{~m} / \mathrm{s}$.

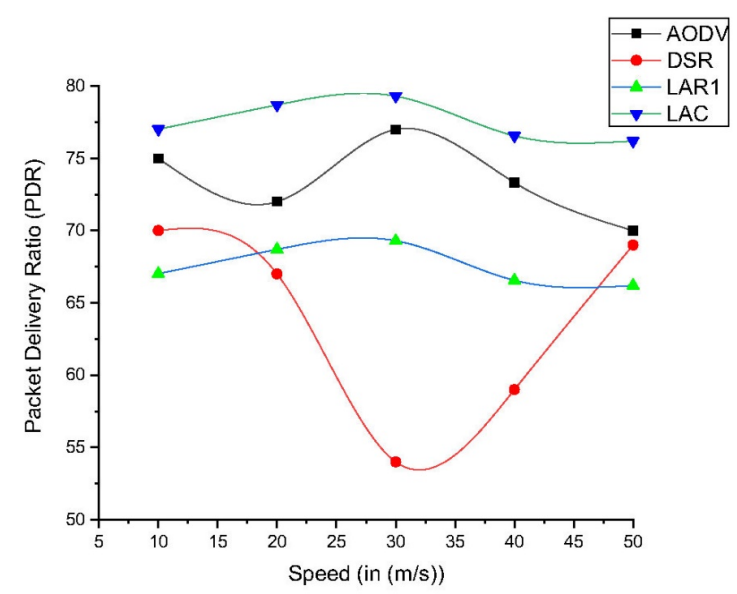

Figure 3: PDR for 60 Nodes with Changing Node Speed.

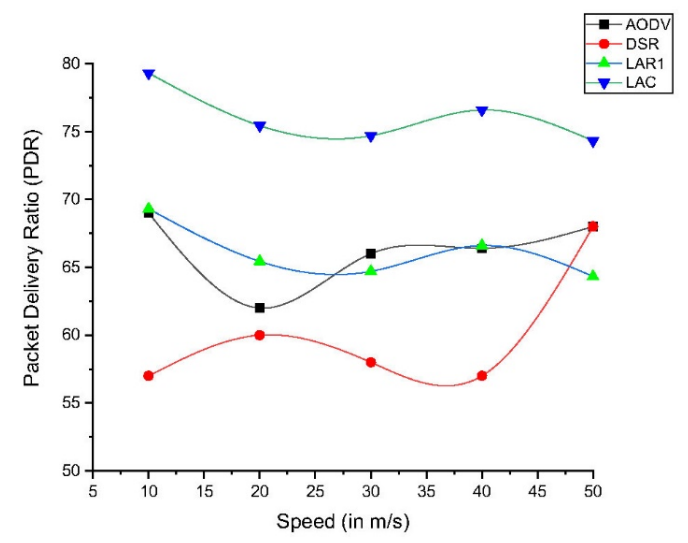

Figur 4: PDR for 80 Nodes with Changing Node Speed. 
In Figure.4, shows the PDR for 80 nodes with various node densities. LAC protocol performance with higher speed is constant above $75 \%$. But the performance of DSR and LAR1 protocol performance is below $70 \%$.

In Figure.5, PDR for 100 nodes is shown. From the results, it is visible that with different node speed performance of LAC protocol is almost constant nearly $75 \%$ above. The performance of AODV, DSR and LAR1 protocol performance is below $70 \%$.

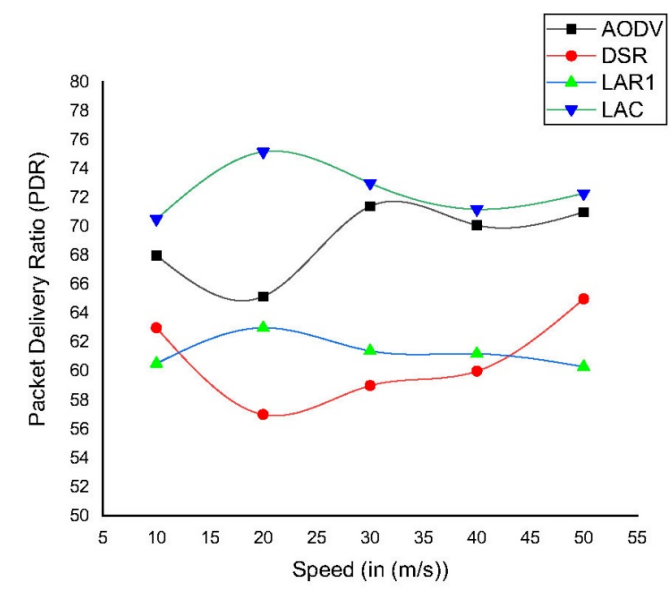

Figure 5: PDR for 100 Nodes with Changing Node Speed.

\section{Dense Traffic Scenario}

In this dense traffic scenario, we have only considered node 120 and 150 nodes for the performance analysis.

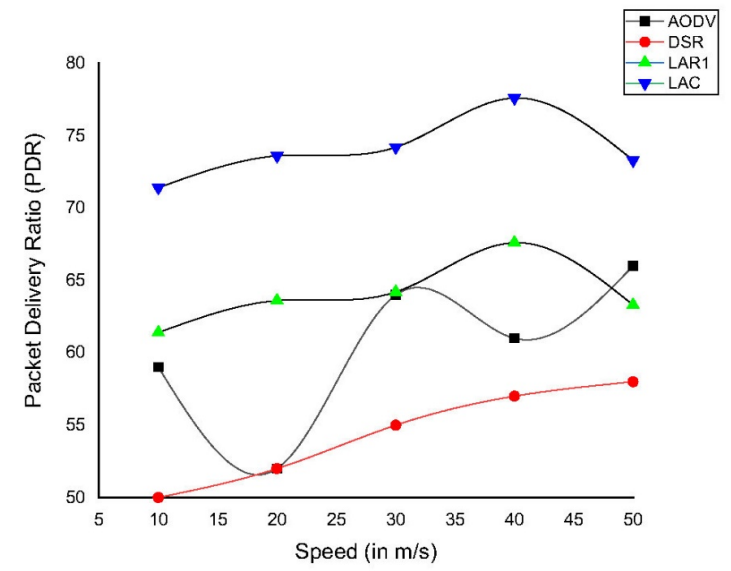

Figure 6: PDR for 120 Nodes with Changing Node Speed.

In Figure.6, shows PDR of moderate traffic scenario for node 120. From the results, it shows LAC protocol performs well up to node speed $30 \mathrm{~m} / \mathrm{s}$ as well as AODV protocol. At high- speed performance of LAC protocol decreases. But significance improvement is noticed for LAR1 protocol. 


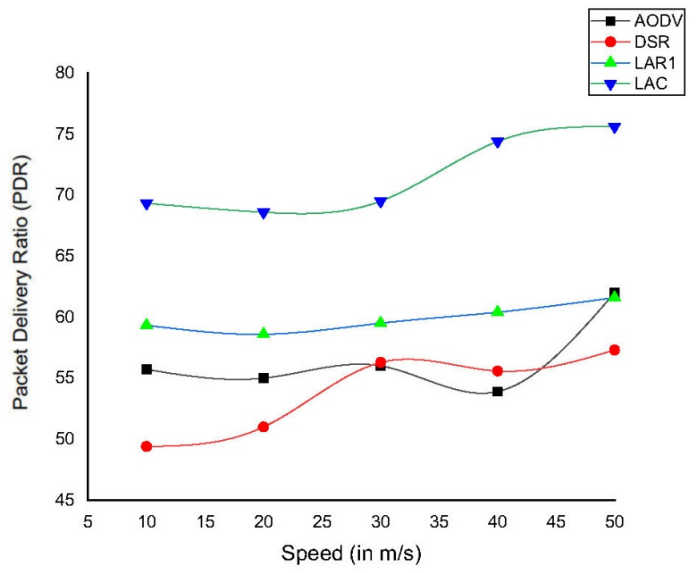

Figure 7: PDR for 150 Nodes with Changing Node Speed.

In Figure.7, shows the PDR of routing protocols with changing node speed. The performance of LAC protocol is constant up to $30 \mathrm{~m} / \mathrm{s}$ node speed and afterward with higher node speed PDR gradually improved. All the protocol performed well in high node speed $50 \mathrm{~m} / \mathrm{s}$. Overall, the performance of LAC protocol performs better in various node speeds.

It unmistakably creates the impression that from all the cases LAC gives better execution as far as PDR. This may mirror the requirement for enhancing the number of nodes in the system to give better execution through the LAC steering protocol. Table-4 shows the PDR values for different routing protocols.

Table 4: PDR of Various Protocols

\begin{tabular}{|c|c|c|c|c|c|c|}
\hline Routing Protocols & No. of Nodes & Speed 10 & Speed 20 & Speed 30 & Speed 40 & Speed 50 \\
\hline \multirow{6}{*}{$A O D V$} & 50 & 69.00 & 72.00 & 76.00 & 73.33 & 72.00 \\
\hline & 60 & 75.00 & 72.00 & 77.00 & 73.32 & 70.00 \\
\hline & 80 & 69.00 & 62.00 & 66.00 & 66.40 & 68.00 \\
\hline & 100 & 68.00 & 65.17 & 71.40 & 70.10 & 71.00 \\
\hline & 120 & 59.00 & 52.00 & 64.00 & 61.00 & 66.00 \\
\hline & 150 & 55.72 & 55.00 & 56.00 & 53.90 & 62.00 \\
\hline \multirow{6}{*}{$D S R$} & 50 & 64.00 & 60.00 & 55.00 & 57.00 & 68.00 \\
\hline & 60 & 70.00 & 67.00 & 54.00 & 59.00 & 69.00 \\
\hline & 80 & 57.00 & 60.00 & 58.00 & 57.00 & 68.00 \\
\hline & 100 & 63.00 & 57.00 & 59.00 & 60.00 & 65.00 \\
\hline & 120 & 50.00 & 52.00 & 55.00 & 57.00 & 58.00 \\
\hline & 150 & 49.40 & 51.00 & 56.28 & 55.58 & 57.30 \\
\hline \multirow{6}{*}{ LARl } & 50 & 69.52 & 68.16 & 69.20 & 67.60 & 67.32 \\
\hline & 60 & 67.02 & 68.70 & 69.30 & 66.56 & 66.20 \\
\hline & 80 & 69.31 & 65.44 & 64.70 & 66.60 & 64.32 \\
\hline & 100 & 60.52 & 63.00 & 61.40 & 61.20 & 60.30 \\
\hline & 120 & 61.40 & 63.60 & 64.20 & 67.60 & 63.30 \\
\hline & 150 & 59.33 & 58.59 & 59.50 & 60.40 & 61.60 \\
\hline \multirow{6}{*}{$L A C$} & 50 & 79.52 & 78.16 & 79.20 & 77.60 & 77.32 \\
\hline & 60 & 77.02 & 78.70 & 79.30 & 76.56 & 76.20 \\
\hline & 80 & 79.31 & 75.44 & 74.70 & 76.60 & 74.32 \\
\hline & 100 & 70.52 & 75.17 & 71.40 & 71.20 & 70.30 \\
\hline & 120 & 71.40 & 73.60 & 74.20 & 77.60 & 73.30 \\
\hline & 150 & 69.33 & 68.59 & 69.50 & 74.40 & 75.60 \\
\hline
\end{tabular}




\section{CONCLUSIONS}

In our analysis, we have demonstrated the execution correlation of LAC, AODV, LAR1 and DSR protocol for VANETs. For better practical analysis of these protocols, intelligent driver model with street crossing point is thought of. The presentation of these protocols is altogether concentrated with changing node speeds and traffic density. Our outcome analysis it is unmistakably apparent that when the system is meagrely populated the effective conveyance of the message is almost $79.52 \%$ in the LAC protocol. Further, the presentation of LAC in moderate and thick rush hour gridlock situation is high when contrasted with others. In this way, the outcomes show that LAC outflank LAR1, DSR and AODV in terms of PDR. We can reason that location based protocol is better with regards to VANET.

\section{REFERENCES}

1. Qingzi Liu; Qiwu Wu; Li Yong, "A hierarchical security architecture of VANET," Cyberspace Technology (CCT 2013), International Conference on, vol., no., pp.6,10, 23-23 Nov. 2013

2. Francesca Cuomo, Izhak Rubin, Andrea Baiocchi, Pierpaolo Salvo, Enhanced VANET broadcast throughput capacity via a dynamic backbone architecture, Ad Hoc Networks, Volume 21, October 2014, Pages 42-59.

3. Sharma, Vishal, Harsukhpreet Singh, and M. Kaur. "Implementation and Analysis of OFDM based IEEE $802.11 \mathrm{~g}$ VANET." IJCNWMC, Trans-Tellar (2013): 47-54.

4. Christian Lochert, Hannes Hartenstein Jing Tian, HolgerFüßler, Dagmar Hermann, and Martin Mauve, "A Routing Strategy for Vehicular Ad Hoc Networks in City Environments, " In the Proceedings of IEEE Intelligent Vehicles Symposium, 2003, pp.156-161.

5. F.DeRango, A.ha, A.Molinaro,and S. Marano, "A Modified Location Aided Routing Protocol for the Reduction of Control Overhead in Ad-hoc Wireless Networks," ICT2003, vol.2, February 23 -March 1,2003, pp. 1033-1037.

6. Sidi-Mohammed Senouci and Tinku Mohamed Rasheed, "Modified Location Aided Routing protocols for control overhead Reduction in Mobile Ad Hoc networks," In the International Federation for Information Processing, Vol.229, 2007, pp. 137146.

7. Neng-Chung Wang, Jong-Shin Chen, Yung-Fa Huang, and Si-Ming Wang, "A Greedy Location Aided Routing Protocol for Mobile Ad Hoc Networks," In proceedings of the 8th WSEAS International Conference on Applied Computer and Applied Computational Science (ACACOS '09) Hangzhou, China, 2009, pp 175-180.

8. Y.B. Ko and N. Vaidya, "Location-aided routing (LAR) in mobile ad hoc networks," ACM/IEEE, MOBICOM'98, 1998, pp. 66-75.

9. J. Broch, D. Johnson, and D. Maltz. "The Dynamic Source Routing Protocol for Mobile Ad Hoc Networks," http://www.ietf.org/internetdrafts/draft-ietfmanet-dsr-03.txt, IETF Internet draft, Oct. 1999.

10. C. E. Perkins and E. M. Royer, “Ad Hoc On-demand Distance Vector Routing,” Proc. 2nd IEEE Wksp. Mobile Comp. Sys. AndApps., Feb.1999, pp. 90-100.

11. Rahul Kumar Chawda and Dr Ghanshyam Thakur "Road Side Unit Prevention Mechanism For DDOS Attack Using Artificial Bee Colony”, Jour of Adv Research in Dynamical \& Control Systems, 02-Special Issue, 2019, pp. 1341-1357.

12. UCLA,Glomosim. http://pcl.cs.ucla.edu/projects/glomosim 
13. J. Haerri, F. Filali, C. Bonnet, and Marco Fiore, "VanetMobiSim: Generating Realistic Mobility Patterns for VANETs," in the proceedings of the 3rd international workshop on Vehicular ad hoc networks VANET'06, September 29, Los Angeles, California, USA, 2006, pp.96- 97.

14. Jerome Harri, FethiFilali and Christian Bonnet, "Mobility Models for Vehicular Ad Hoc Networks: A Survey and Taxonomy," EURECOM, March 26, 2007, pp.19-41. 